DOI: https://doi.org/10.46667/renbio.v13i1.267

\title{
Teorias da Aprendizagem na Prática Pedagógica do Professor de Biologia
}

\author{
Theory of Learning in the Pedagogical Practice of the Teacher of Biology
}

Gessikelli Silva Barbosal, Arthur Lima da Silva ${ }^{2}$

\begin{abstract}
Resumo
Este estudo objetivou analisar quais teorias da aprendizagem os professores de Biologia do município de Surubim/PE, conhecem e aplicam em sala de aula. Participaram do estudo 10 professores de Biologia que atuam na rede estadual de ensino. A pesquisa foi do tipo exploratória, de abordagem qualitativa. $\mathrm{Na}$ coleta de dados foram utilizadas entrevistas semiestruturadas com perguntas de cunho pessoal e questões relacionadas aos objetivos da pesquisa. Para análise dos dados foi seguida a proposta do método hermenêutico-dialético segundo Minayo (1992). Os resultados mostraram que os professores de Biologia possuíam um conhecimento fragmentado sobre as teorias da aprendizagem, e que isto pode ter sido ocasionado pela falta de interesse nas disciplinas pedagógicas, durante a formação inicial dos mesmos.
\end{abstract}

Palavras-chave: Formação de Professores. Educação. Ensino Médio.

\begin{abstract}
This study aimed to analyze which learning theories biology teachers from Surubim / PE know and apply in the classroom. Ten biology teachers who work in the state school system participated in the study. The research was exploratory, qualitative approach. In the data collection, semi-structured interviews with personal questions and questions related to the research objectives were used. For data analysis was followed the proposal of the hermeneutic-dialectical method according to Minayo (1992). The results showed that biology teachers had a fragmented knowledge about learning theories, and this may have been caused by the lack of interest in the pedagogical subjects during their initial formation.
\end{abstract}

Keywords: Teacher training; Education; High school.

\footnotetext{
${ }^{1}$ Mestre em Educação - Universidade de Pernambuco (UPE). Recife, PE, Brasil. Professora contratada Universidade de Pernambuco (UPE). Recife, PE, Brasil. E-mail: gessikellisb@gmail.com

${ }^{2}$ Doutorando em Ecologia e Biomonitoramento - Universidade Federal da Bahia (UFBA). Salvador, BA Brasil. Professor Assistente Universidade Federal do Vale do São Francisco (UNIVASF). São Raimundo Nonato, PI - Brasil. E-mail:
}

Submetido em: 07/11/2019 - Aceito em: 05/06/2020 
DOI: $\underline{\text { https://doi.org/10.46667/renbio.v13i1.267 }}$

\section{Introdução}

A identidade de um professor é construída a partir de elementos do próprio sujeito e do meio no qual ele está inserido. Na formação inicial, os estudantes de cursos de licenciatura são convidados a conhecer diversos teóricos da educação, que trazem teorias de aprendizagem que podem auxiliar o trabalho do professor, uma vez que, tendo conhecimento das contribuições das teorias da aprendizagem, é possível trabalhar com uma abordagem integrativa do ensinoaprendizagem (OGASAWARA, 2009). De acordo com Carvalho (2003), as teorias da aprendizagem contribuem para a compreensão do processo de ensino e aprendizagem referente à criança, jovem ou adulto, levando em conta o desenvolvimento, a faixa etária e os aspectos psicossociais e cognitivos.

Nos cursos de licenciatura, as teorias da aprendizagem são comumente estudadas na disciplina de Psicologia da Educação, focando nos distintos modos de compreender o processo de ensino e aprendizagem (LUCION; FROTA; SILVA, 2012). Elas contribuem com informações precisas sobre o que saber acerca de como os indivíduos aprendem, integrando um grupo de saberes que é fundamental para os futuros docentes. Portanto, para o educador, essas informações tornam-se meios de conhecer maneiras eficazes de ensinar (PITTENGER; GOODING, 1977).

As teorias da aprendizagem estabelecem ainda relação com as práticas pedagógicas, refletindo sobre o modo como as teorias estudadas questionam e se relacionam de forma crítica com as práticas dos professores em sala de aula, para que possam se aprofundar no saber pedagógico do ensino e aprendizagem, tendo respaldo nas teorias que explicam as práticas e contribuem para a compreensão dos processos de aprendizagens nas diferentes dimensões do fazer pedagógico (NETTO; COSTA, 2017).

Contudo, é compreensível que no âmbito educacional não exista apenas uma teoria capaz de responder a todas as dúvidas e questões vividas no ambiente de sala de aula. Coll (1997) aponta uma saída para essa situação. Para este autor devemos evitar fazer uma junção impensada das teorias e, ao mesmo tempo, não podemos nos apegar unicamente a contribuições de apenas uma abordagem.

Assim, todo conhecimento adquirido pelo professor, tanto na formação inicial como continuada, em conjunto com as suas experiências, vão refletir no modo como este conduzirá a sua prática. De acordo com Vaillant e Marcelo (2012, p.75) "as práticas de ensino seguem sendo o elemento mais valorizado, tanto pelos docentes em formação como em exercício, com relação aos diferentes componentes do currículo formativo". Depois de formados, a prática será responsável por demonstrar aos sujeitos as necessidades de aprimoramento constante para o exercício da docência (MACENHAN; TOZETTO; BRANDT, 2016).

Entretanto, para um professor se tornar eficiente ele precisa estar disposto a examinar suas crenças básicas sobre a natureza do homem, da sociedade e da educação. Os docentes devem examinar as semelhanças entre aquilo que acreditam referentes aos propósitos da educação e a informação disponível de como a aprendizagem se processa, a fim de sintetizar 
DOI: $\underline{\text { https://doi.org/10.46667/renbio.v13i1.267 }}$

uma abordagem viável para o ensino. Sem a base de uma metodologia eficiente o profissional estará sujeito a se afundar em técnicas e métodos que podem ou não se adequar à sua personalidade, às necessidades e expectativas de seus alunos, ou às exigências da situação (PITTENGER; GOODING, 1977).

Nos cursos de licenciatura é imprescindível a oferta de disciplinas de cunho pedagógico, voltadas às técnicas de ensino. Contudo, quando a construção do arcabouço de saberes pedagógicos não é favorecida, os futuros profissionais da educação se veem perdidos ao perceberem uma lacuna no seu processo formativo, com relação a falta de conexão entre os componentes pertencentes à matriz curricular do seu curso (VASCONCELOS; LIMA, 2010).

Assim, a formação de professores de Biologia, em sintonia com as exigências contemporâneas, deve estar focada em fazer deles educadores e não técnicos em ciências. Isso não implica dizer que eles não devam se aprimorar nas disciplinas de conteúdos específicos da biologia, entretanto não é o bastante (SCHEID, 2006). Os saberes dos educadores devem ir além dos conhecimentos da matéria que ensina, ou seja, os saberes disciplinares, sendo fundamentais os saberes da formação profissional, os saberes curriculares e os saberes da experiência (TARDIF, 2008).

Desta forma, foi levantado o seguinte problema de pesquisa: Quais teorias da aprendizagem os professores de biologia conhecem e têm aplicado em sua prática pedagógica mediante os conhecimentos adquiridos na sua formação inicial e continuada? Visto que é importante compreender em que está embasado a prática pedagógica do professor, faz-se necessário aprofundar os conhecimentos que regem a sua prática de ensino e de que forma podem auxiliar na melhoria das estruturas dessas práticas.

Partindo do pressuposto de que as teorias da aprendizagem, assim como outros conteúdos pedagógicos, são apreendidos de forma fragmentada durante a formação inicial do professor de biologia, influenciando diretamente nas suas práticas de ensino, tivemos como objetivo geral, analisar quais teorias da aprendizagem os professores de Biologia do município de Surubim, Pernambuco, conhecem e aplicam em sala de aula.

\section{Algumas teorias da aprendizagem}

As teorias da aprendizagem resultam das tentativas da psicologia na busca em compreender o comportamento humano e os processos de aprendizagem. As teorias envolvem muitos conceitos e princípios, que as tornam abrangentes, "subjacentes às teorias estão sistemas de valores que se pode chamar de filosofias ou visões de mundo" (MOREIRA, 2015, p. 13). Com relação as teorias de aprendizagem são três filosofias subjacentes: a comportamentalista (behaviorismo), a humanista e a cognitivista (construtivismo). Contudo, nem sempre é possível classificar uma teoria em apenas uma corrente filosófica (MOREIRA, 2015). Neste estudo, buscaremos fazer um breve levantamento de cada uma destas correntes filosóficas, trazendo alguns exemplos de teorias que estão correlacionadas. 
DOI: https://doi.org/10.46667/renbio.v13i1.267

Para isso, podemos recorrer ao início dos anos 1900, quando psicólogos começaram a rejeitar temas como mente e pensamento, passando a concentrar-se nos aspectos mais objetivos do comportamento. Eles pretendiam buscar "uma psicologia científica que lidasse exclusivamente com os atos comportamentais observáveis e passíveis de descrição objetiva, por exemplo, em termos de 'estímulos' e 'respostas"' (SCHULTZ; SCHULTZ, 2006, p. 228). A esse movimento deu-se o nome de behaviorismo, sendo o seu principal líder Jonh B. Watson.

De acordo com Lefrançois (2012) Watson contribuiu para fazer da ciência da psicologia mais rigorosa e objetiva, propagando a noção de que as experiências ambientais são grandes potenciais para mudar padrões comportamentais e criou um modelo de aprendizagem (condicionamento clássico) que explica alguns aspectos dos comportamentos animal e humano.

A forte convicção de que são as experiências que determinam tudo o que as pessoas fazem e sabem, leva a crença de que todos os seres humanos são iguais, assim qualquer um pode conseguir êxito, e isso depende apenas das suas experiências e das oportunidades que lhe é concedida. Assim, pode-se dizer que Watson subestimava o papel da hereditariedade (LEFRANÇOIS, 2012). O behaviorismo de Watson constitui o primeiro estágio da escola de pensamento comportamental, contudo, não foi o único representante (NOGUEIRA; LEAL, 2015).

Dentre os behavioristas Skinner foi o mais estudado e durante décadas foi considerado um dos psicólogos mais influentes no mundo, sendo o responsável pela ampliação do behaviorismo ao propor e construir o behaviorismo radical. De acordo com Pittenger e Gooding (1977) Skinner decidiu examinar o desenvolvimento do comportamento dos organismos a partir do ponto de vista exterior, operacional. Assim, Skinner desenvolveu o conceito de Comportamento Operante, sendo este o cerne principal da análise do comportamento.

De acordo com Ogasawara (2009) para compreender o conceito de comportamento operante, se faz necessário entender o condicionamento operante, que segundo a autora pode ser definido como o processo no qual busca condicionar a resposta de um indivíduo, seja ele para aumentar a probabilidade de ocorrência ou para extingui-la. Assim, quando o sujeito apresenta uma resposta adequada, são apresentados reforços, o conceito de reforço aqui está ligado a ocorrência da resposta, pois um estímulo só pode ser considerado reforçador se ele aumenta a probabilidade do comportamento ocorrer. O reforço pode ser considerado positivo, quando apresenta algo ao indivíduo ou negativo, quando se retira algo do ambiente (OGASAWARA, 2009).

Na teoria de Skinner era considerado também a extinção do condicionamento operante. Segundo Skinner (2003) quando o reforço já não está sendo dado, a resposta se tornará cada vez menos frequente - extinção operante. De modo geral, as teorias do comportamento ou behavioristas podem nos oferecer subsídios para pensarmos uma educação que considere as particularidades de cada aluno em sala de aula, na medida em que procura acabar com o 
DOI: $\underline{\text { https://doi.org/10.46667/renbio.v13i1.267 }}$

sofrimento de cada um quando apresenta algum tipo de dificuldade ao longo do processo, e do professor, quando buscar um planejamento aberto a modificações (NOGUEIRA; LEAL, 2015).

A corrente filosófica cognitivista por sua vez, dá ênfase àquilo que é rejeitado pela visão behaviorista: a cognição, o ato de conhecer, como o ser humano conhece o mundo (MOREIRA, 2015). O surgimento do cognitivismo se dá praticamente na mesma época do behaviorismo, em contraposição a ele, mas também como uma reação ao mentalismo da época que buscava estudar o que os indivíduos pensavam e sentiam.

Como exemplo de uma teoria cognitivista temos a epistemologia genética de Jean Piaget, segundo ela através de interações contínuas do sujeito com o mundo, é construído o conhecimento e desenvolvida a inteligência, por meio de sucessivas assimilações, acomodações e equilibrações. $O$ desenvolvimento da inteligência e do raciocínio-lógico, encontra-se organizado em quatro estruturas de pensamento: o estágio sensório-motor que compreende de 0 a 2 anos de idade, aproximadamente; o estágio pré-operatório de 2 aos 7 anos, aproximadamente; o estágio operacional-concreto dos 7 aos 12 anos, e o estágio operacional formal, a partir dos 12 anos de idade (NOGUEIRA; LEAL, 2015).

Contudo, a intenção de Piaget não era criar uma teoria da aprendizagem, mas a sua teoria do desenvolvimento humano poderia auxiliar os professores a compreender os processos de aprendizagem de seus alunos ao propor atividades de acordo com o estágio em que seu aluno se encontra. Ainda, de acordo com Nunes e Silveira (2008, p. 89):

\begin{abstract}
Uma contribuição central de Piaget à área educacional diz respeito à ideia de que o ser humano constrói ativamente seu conhecimento acerca da realidade externa e de que as interações entre os sujeitos são um fator primordial para o seu desenvolvimento intelectual e afetivo. Transpondo esta afirmação para uma situação educacional, significa dizer que existe uma ênfase no aluno, em suas ações, seus modos de raciocínio, de como interpreta e soluciona situações-problema. Esta ideia o posicionamento no lugar de ativo em seu processo de aprendizagem. Ao mesmo tempo, dada a ênfase nas interações, nos intercâmbios entre os sujeitos, o professor, assim como os próprios companheiros de classe, são peças fundamentais para a construção do conhecimento (NUNES; SILVEIRA, 2008, p. 89).
\end{abstract}

Assim, apesar de Piaget não ter uma teoria capaz de servir como um modelo a ser seguido em sala de aula, seus estudos tem sido amplamente discutidos e conhecidos por pedagogos, e tem os auxiliado no processo de compreensão do desenvolvimento humano. Já Vygotsky foi um dos primeiros autores a diferenciar o processo de aprendizagem da criança e a formalização da escola. Ele procurou relacionar o aprendizado escolar ao desenvolvimento mental das crianças, com o objetivo de explicar a inter-relação entre os conceitos científicos e os cotidianos, para isso seria necessário analisar o período escolar (NOGUEIRA; LEAL, 2015).

Assim, Vygotsky formula uma nova teoria para relacionar a aprendizagem ao desenvolvimento, baseada em quatro séries de investigações: leitura, escrita e gramática, aritmética, ciências sociais e ciências naturais (NOGUEIRA; LEAL, 2015). 
DOI: $\underline{\text { https://doi.org/10.46667/renbio.v13i1.267 }}$

Vygotsky trouxe profundas contribuições para a compreensão do processo de aprendizagem ao explorar a relação entre o pensamento e a linguagem, a educação para pessoas com deficiência e principalmente ao desenvolver uma nova psicologia com base na historicidade do homem em sua totalidade, onde é possível observar os "sistemas psicológicos que ocorrem no processo de individuação do homem inserido social e historicamente em uma cultura" (MOLON, 1999, p. 21).

Outro teórico pioneiro em construir uma teoria da aprendizagem voltada para sala de aula foi David Ausubel, trazendo grandes contribuições por meio da aprendizagem significativa. De acordo com Ausubel o conhecimento prévio do aluno é a variável mais importante para a aprendizagem significativa de novos conteúdos, de maneira em que os estudantes façam uso dos significados já internalizados de forma substantiva e não arbitrária. Nesse processo, ao mesmo tempo em que vai passo a passo diferenciando sua estrutura cognitiva, está também fazendo a reconciliação integradora, identificando semelhanças e diferenças, reorganizando seu conhecimento, ou seja, o aprendiz constrói o seu próprio conhecimento (MOREIRA, 2015).

Os organizadores prévios são também importantes para uma aprendizagem significativa, estes podem ser entendidos como um material introdutório apresentado aos alunos antes do conteúdo a ser apreendido. O organizador é um conceito que precede o conteúdo, consiste em informações amplas e genéricas, que servirão de pontes de ancoragem para a ideia mais específica, que virão ao decorrer de uma aula (NOGUEIRA; LEAL, 2015).

Ausubel também organizou um tipo de ensino utilizando o que por ele foi denominado de mapas conceituais, os quais constituem em diagramas que indicam a relação entre conceitos. Assim, mapas conceituais "podem ser vistos como diagramas hierárquicos que procuram refletir a organização conceitual de uma disciplina ou parte de uma disciplina" (MOREIRA; MASINI, 1982, p. 45).

Além de Ausubel, autores como Paulo Freire também defende a importância do conhecimento prévio dos estudantes. Freire trouxe grandes contribuições para a educação brasileira, como também sua pedagogia tem influenciado outros países. As concepções de Paulo Freire sobre educação e ensino são muito atuais e possui implicações para a aprendizagem e o ensino escolar. O discurso pedagógico atual está fundamentado em duas premissas: aprender a aprender e ensino centrado no aluno. Sendo o professor o mediador neste processo, a integração também é fundamental, os conteúdos também são importantes, mas não tanto quanto a significação, ou seja, o sentido em que aquele conteúdo irá proporcionar a sua realidade (MOREIRA, 2015). Assim, o ensino deve fazer sentido para o aluno e os significados devem ser construídos de forma crítica. Isso tudo é defendido por Freire como também pelo autor Carl Rogers, grande representante do humanismo.

De acordo com Nogueira e Leal (2015) Carl Rogers influenciou a história da psicologia moderna, e trouxe contribuições relevantes à tendência humanizadora, para a abordagem psicoterápica, como também para a educação e para o processo de ensino-aprendizagem. 
DOI: $\underline{\text { https://doi.org/10.46667/renbio.v13i1.267 }}$

Rogers vê a facilitação da aprendizagem como o objetivo maior da educação. Ao invés de apresentar uma "teoria da aprendizagem" Rogers propôs uma série de princípios da terapia centrada no cliente (MOREIRA, 2015). Por ter sido professor universitário e terapeuta clínico, Rogers assume uma postura empática e incondicional, tanto com os clientes quanto com os alunos. Para ele "a partir do momento em que aceitamos a nós mesmos, somos capazes de nos transformar e de evoluir em um processo de autorreconstrução intelectual, afetiva e social" (NOGUEIRA; LEAL, 2015, p. 15).

Vale ressaltar que o nosso objetivo não foi descrever minuciosamente cada uma das teorias aqui apresentadas, pois entendemos que cada uma delas são extremamente complexas, contudo, buscamos apresentar de maneira sucinta os principais pontos das teorias que propusemos trabalhar com os professores participantes deste estudo.

\section{Metodologia}

A pesquisa foi do tipo exploratória, orientada por uma abordagem qualitativa, onde Oliveira (2011, p. 41) conceitua como sendo "um processo de reflexão e análise da realidade através da utilização de métodos e técnicas para compreensão detalhada do objeto de estudo em seu contexto histórico e/ou segundo a sua estruturação". A utilização do método qualitativo traz diversas contribuições para o avanço do saber na dinâmica do processo educacional e na sua estrutura de maneira geral.

A pesquisa foi desenvolvida nas escolas da rede pública estadual do município de Surubim/PE, que possui cerca de 64.520 habitantes e está situada no Agreste do estado de Pernambuco, microrregião do Alto do Capibaribe (IBGE, 2018).

No município de Surubim há 8 escolas que ofertam o ensino médio sendo 5 da rede pública estadual e 3 da rede particular. Este estudo foi desenvolvido nas 5 escolas da rede pública de ensino, sendo os sujeitos da pesquisa os docentes de Biologia. No total foram entrevistados 10 profissionais, sendo 9 do sexo feminino e 1 do sexo masculino, com faixa etária média de 44 anos, variando entre 31 e 57 anos de idade. Todos os professores são formados em Licenciatura em Ciências Biológicas e possuem cursos de pós-graduação a nível de especialização. O tempo médio de atuação na rede de ensino é de 19 anos, variando entre 8 e 37 anos.

Inicialmente, foi realizada uma visita nas escolas estaduais para explicar os objetivos do estudo e solicitar a autorização da direção escolar para a realização da pesquisa. Após essa autorização o trabalho foi submetido ao Comitê de Ética em Pesquisa (CEP) onde foi aprovado sob o número do CAAE: 11714619.6.0000.5196.

Os professores de Biologia foram convidados a assinar o TCLE (termo de consentimento livre e esclarecido) informando concordar com a participação na pesquisa. Em seguida eles participaram de uma entrevista semiestruturada constituída de questões discursivas e de múltipla escolha, sendo as perguntas de cunho pessoal e questões relacionadas aos objetivos da pesquisa. 
DOI: $\underline{\text { https://doi.org/10.46667/renbio.v13i1.267 }}$

As entrevistas foram gravadas para aqueles que concordaram com a sua gravação ou transcritas de acordo com a opção de cada participante. Todas as informações obtidas nas entrevistas foram transcritas para o programa Microsoft Office Word e também para um banco de dados no Microsoft Office Excel, para melhor interpretação dos dados. As respostas das perguntas discursivas foram analisadas e categorizadas, de acordo com a proposta do método hermenêutico-dialético, segundo Minayo (1992). Nesse método a fala dos autores sociais é situada em seu contexto para melhor ser compreendida, tendo como ponto de partida o interior da fala, e de chegada, o campo da especificidade histórica e totalizante que ela produz (MINAYO, 2002). Para preservar a identificação dos sujeitos participantes será utilizado as siglas P1 (Professor 1), P2 (Professor 2), e assim por diante.

\section{Resultados e discussões}

\subsection{As Teorias da Aprendizagem segundo os professores de Biologia}

Com relação as concepções dos professores acerca das teorias da aprendizagem, apenas um professor não soube e não tentou dizer, ao menos pela etimologia da palavra, o que seria teorias da aprendizagem. No geral os professores definiram o termo "teorias da aprendizagem" como processos, conceitos ou métodos que envolvem o processo de aprendizagem. Contudo, algumas definições merecem destaque com relação às teorias da aprendizagem, como vemos a seguir:

\footnotetext{
Acredito que seja procedimentos de estudo, como se fosse uma teoria científica, no qual a gente deve ter um passo-a-passo para alcançar um conhecimento mais concreto, como se fosse uma lei científica (P1).
}

Talvez seja a forma de passar o conteúdo para o aluno, na verdade eu não consigo dizer o que possa ser (...) (P2).

As teorias da aprendizagem no meu entendimento seriam os conteúdos programáticos em que os alunos iriam absorver esses conteúdos de uma forma apenas teórica, não indo para uma prática (P10).

Resultados semelhantes foram encontrados dos estudos de Lucion, Frota e Silva (2012) onde os professores de ciências da natureza não conseguiram conceituar satisfatoriamente o termo "teorias da aprendizagem". De acordo com Moreira (2015, p. 12) teorias de aprendizagem é, "uma construção humana para interpretar sistematicamente a área de conhecimento que chamamos de aprendizagem". Elas representam um ponto de vista de um autor ou pesquisador sobre como interpretar o tema aprendizagem, como também as variáveis independentes, dependentes e intervenientes, bem como tentar explicar o que é aprendizagem e porque funciona como funciona. Ou seja, teorias da aprendizagem não são como uma receita a ser seguida ou um manual de "passo-a-passo", também não é a forma como o professor "passa o conteúdo para o aluno", tampouco "conteúdos programáticos em que os alunos irá absorver”, como foi relatado pelos entrevistados. 
DOI: https://doi.org/10.46667/renbio.v13i1.267

Os professores também foram questionados se durante a sua graduação, as teorias da aprendizagem foram ensinadas/aprendidas de forma satisfatória. Dos 10 entrevistados, 04 afirmaram que as teorias foram ensinadas/aprendidas de forma satisfatória, mas pela falta de interesse dos próprios entrevistados e com o passar dos anos essas teorias foram sendo esquecidas. Os demais professores, 06 do total afirmaram que esse conteúdo era visto de forma fragmentada e/ou descontextualizada. De acordo com Lucion, Frota e Silva (2012) a defasagem dos conteúdos na disciplina de Psicologia da Educação, podem não possibilitar a internalização dos principais conceitos das teorias da aprendizagem. Isto foi constatado em nossos estudos, quando questionamos sobre quais teorias da aprendizagem os professores conheciam e com quais delas se identificam. Apenas 03 dos 10 entrevistados conseguiram responder, porém, um dos professores citou Piaget, o segundo citou Piaget e Vygotsky e o terceiro citou a psicanálise e o construtivismo como teorias da aprendizagem, sendo que nenhum destes três professores conseguiram mencionar nenhuma teoria de forma específica ou ainda, se tinham alguma afinidade com alguma teoria.

De acordo com Moreira (2015), na prática o termo teoria de aprendizagem é usado sem muito rigor. Como exemplo, temos a teoria de Jean Piaget que apesar de ser muitas vezes rotulada como uma teoria da aprendizagem e ter suas contribuições no campo educacional, trata-se na verdade de um teoria do desenvolvimento cognitivo.

Também foi questionado aos professores se em sua prática profissional, ele conseguia identificar influências de alguma das teorias da aprendizagem. Apenas uma professora conseguiu responder, em suas palavras:

Freud ou Vygotsky se não me engano falava que para a gente aprender devemos ter um pré-conhecimento, e que quando vamos para a sala de aula já trazemos alguma bagagem desse conhecimento (P7).

Todavia, este conceito é bem mais utilizado em outras teorias como a teoria da aprendizagem significativa de David Ausubel ou as Teorias humanistas de modo geral. Segundo os autores destas teorias é fundamental valorizar e utilizar o conhecimento prévio dos alunos e que eles ao chegarem na sala de aula já possuem um conhecimento que é adquirido fora da escola. De acordo com Pittenger e Gooding (1977) os teóricos em educação e Psicologia têm sido criticados por não terem ofertado teorias da aprendizagem e do comportamento que pudessem ser aplicadas de forma pronta à instrução normal em sala de aula. Os autores ainda concordam que as teorias são imperfeitas e difíceis de aplicar, mas afirmam a importância do conhecimento destas teorias e asseguram que as técnicas usadas em sala de aula sem fundamento científico são fragmentárias e o que é pior, inibem a aprendizagem ao invés de facilitá-la.

Assim como Pittenger e Gooding (1977), todos os professores entrevistados em nosso estudo acreditam que as teorias da aprendizagem poderiam contribuir de forma significativa para a prática de ensino se eles tivessem um conhecimento mais aprofundado sobre elas. Quando questionada a esse respeito uma professora acrescentou: 
DOI: https://doi.org/10.46667/renbio.v13i1.267

Embora a gente não esteja ligado ao significado real de cada uma, acho que na prática a gente acaba trabalhando com isso, apesar da gente não ter em mente o que é a teoria de cada um, de cada cientista, de cada autor, mas na realidade elas estão impregnadas na nossa prática mesmo sem saber associa-las (P9).

De fato é possível que no âmbito educacional não exista apenas uma teoria capaz de responder a todas as dúvidas e questões vividas no ambiente de sala de aula. Contudo, Coll (1997) afirma que devemos evitar fazer uma junção impensada das teorias e, ao mesmo tempo, não podemos nos apegar unicamente à contribuições de apenas uma abordagem. Mas, como utilizar as teorias da aprendizagem no ambiente escolar se afirmamos não ter o conhecimento que julgamos suficiente para isso?

Ainda na entrevista, foram mencionadas algumas correntes filosóficas como Behaviorismo, Cognitivismo, Construtivismo e Humanismo, onde utilizamos 3 categorias nas quais os professores deveriam responder. São elas: lembro das correntes filosóficas, mas não sei conceituar; lembro e conceituo, mas não aplico em sala de aula e lembro, conceituo e aplico em sala de aula. Na primeira categoria os professores citaram as correntes filosóficas das quais lembravam mas não conseguiam conceituar, como está representado no gráfíco:

Gráfico 1: Número de menções das correntes filosóficas em que os professores de biologia lembraram, mas não conseguiram conceituar.

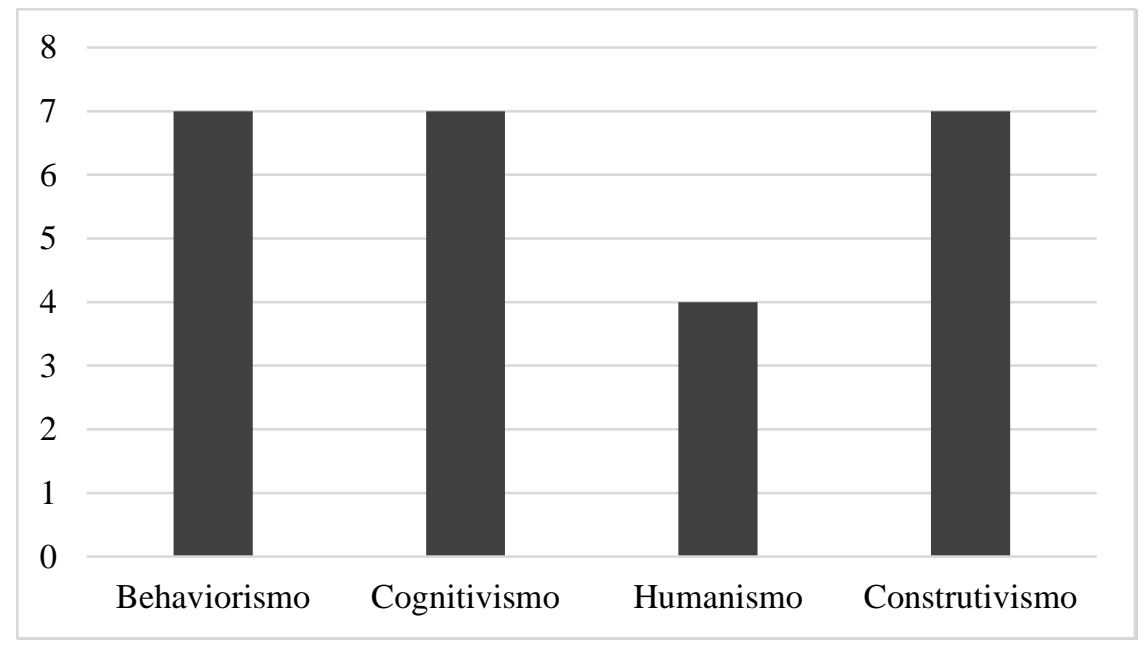

Fonte: organizado pelos pesquisadores (2019), a partir dos dados coletados em pesquisa.

A soma das citações ultrapassam o número total dos entrevistados (10) porque cada um deles tiveram a opção de citar mais de um autor conforme iam sendo lembrados pelos mesmos. Como mostrado no gráfico, o behaviorismo assim como o cognitivismo e construtivismo foram mencionados por 07 professores, contudo, apenas 04 dos 10 professores afirmam lembrar do humanismo. Resultados semelhantes foram encontrados nos estudos de Lucion, Frota e Silva (2012), onde o humanismo foi uma das filosofias menos recordadas pelos professores entrevistados. Neste estudo, somente uma professora dentre os 10 entrevistados afirmou que o professor de Psicologia da Educação na sua formação inicial abordava bastante o humanismo, mas ela não soube mencionar nenhuma teoria. Este resultado é curioso, uma vez que a filosofia humanística considera primordialmente o aluno como pessoa. Nela o ensino facilita a 
DOI: $\underline{\text { https://doi.org/10.46667/renbio.v13i1.267 }}$

autorrealização e o crescimento pessoal. Ela pode ainda transcender e englobar os três tipos de filosofias, a cognitiva, a afetiva e a psicomotora, assim como a teoria de Carl Rogers, que deu origem ao chamado "ensino centrado no aluno" e o "aprender a aprender", presentes na pedagogia de Paulo Freire, tão discutida na atualidade (MOREIRA, 2015).

Com relação à segunda categoria lembro e conceituo, mas não aplico em sala de aula, nenhum dos professores mencionou alguma filosofia. Isso nos revela a falta de conhecimentos acerca das teorias da aprendizagem, ou até mesmo dificuldades de relacioná-las a suas práticas pedagógicas, já que os entrevistados poderiam lembrar e saber conceituar mas por não concordar com elas não aplica-las em sua prática.

Já na terceira categoria lembro, conceituo e aplico em sala de aula 02 professores afirmaram saber conceituar e aplicar, mas algumas colocações acabaram fugindo muito do que realmente se trata cada uma dessas abordagens, podemos observar isso na fala de P2 quando tenta conceituar as filosofias cognitivistas, construtivistas e humanísticas:

\section{Cognitivismo - o aluno traz o aprendizado para as séries seguintes}

Construtivismo - É a maneira com que o aluno vai construir e desenvolver o conhecimento.

Humanista - é essas coisas novas de hoje, tipo direitos humanos (P2).

Quando questionada sobre como ela aplicava ou observava estas abordagens P2 falou que todas elas eram observadas em sala de aula, porém afirmou não saber identificar e dizer de forma específica como, relatando ainda que muitas são usadas pelos professores sem que estes saibam. Desse modo, verificamos que a professora respondeu a essa questão baseada naquilo que acredita, portanto, percebe-se a dificuldade e talvez a falta de segurança para identificar e relacionar as teorias com a sua prática de ensino, uma vez que ela afirmou saber conceituar, mesmo que de forma errônea, porém levou estes conceitos para a sua prática de forma generalizada. Outra professora também buscou conceituar a filosofia construtivista, conforme sua fala:

Construtivismo, não lembro muito bem, mas sei que fala que a gente vai construindo os conceitos e aprendizagens ao decorrer da nossa vida, aquilo que a gente vê, vai sendo construindo (P9).

Moreira (2015) define o construtivismo como uma posição filosófica cognitiva interpretacionista, e enfatiza que na sala de aula o construtivismo tem sido confundido com "método construtivista", "aprendizagem por descoberta" ou ainda o que é pior, com o simples fato do aluno manipular atividades na ingenuidade de que ao fazer isso ele está "construindo". Para este autor o que existe são metodologias e teorias construtivistas, consistentes com a postura filosófica construtivista (MOREIRA, 2015). A professora (P9) também acredita que as teorias da aprendizagem estão presentes em sala de aula, mas na maioria das vezes não são percebidas e identificadas pelos professores. 
DOI: $\underline{\text { https://doi.org/10.46667/renbio.v13i1.267 }}$

Em uma das questões foi solicitado aos participantes da pesquisa que pelo o nome do teórico disponibilizado pela pesquisadora, relatassem se conheciam ou se já ouviram algo sobre eles. Todos os professores entrevistados citaram Vygotsky (10), Jean Piaget (10) e Paulo Freire (10). Já John Watson (2) foi mencionado duas vezes, enquanto Skinner (1), Cal Rogers (1) e David Ausubel (1) foram citados apenas uma vez (Gráfico 2). Contudo, todos os professores relataram que não saberiam falar de forma precisa as teorias de cada autor.

Gráfico 2: Número de citações dos teóricos que os professores de Biologia recordaram

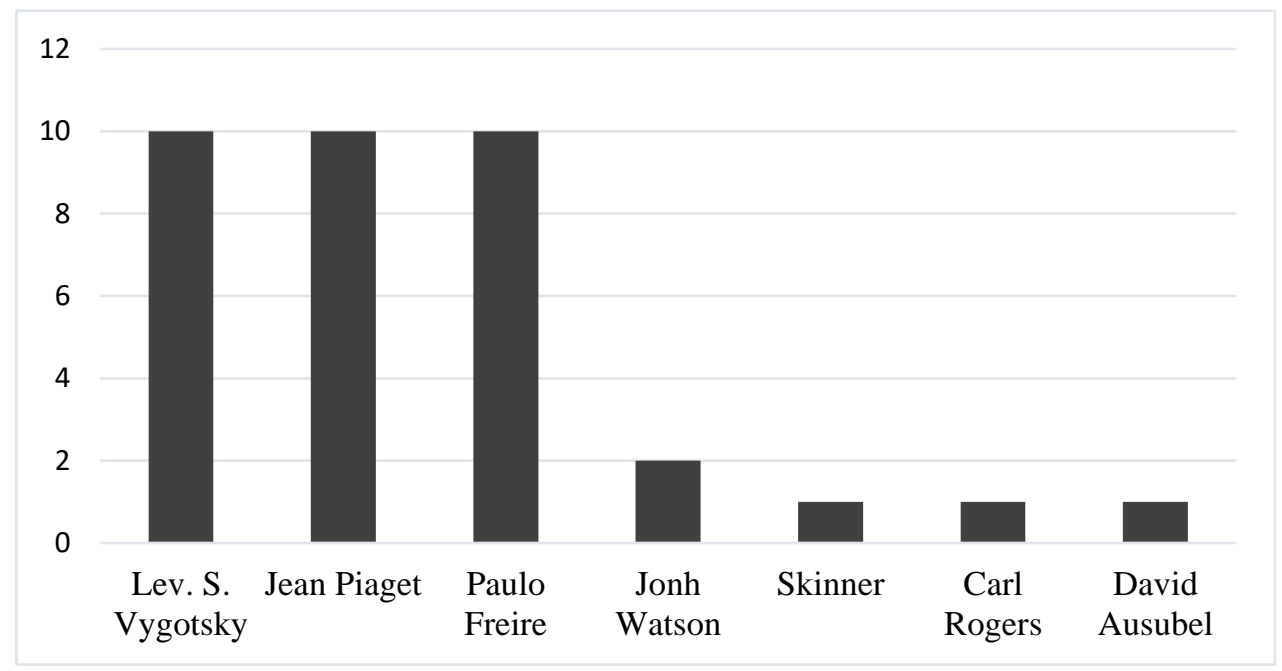

Fonte: organizado pelos pesquisadores (2019), a partir dos dados coletados em pesquisa.

Por meio de outros estudos é possível observar que os professores da educação básica possuem pouco conhecimento com relação às teorias da aprendizagem. Nos estudos de Emmel e Krul (2012) por exemplo, os autores relatam que profissionais da educação dos anos iniciais que participaram de suas pesquisas também possuem pouco conhecimento das teorias de aprendizagem que embasam as suas práticas pedagógicas. Nos estudos de Netto e Costa (2017) 8 de 16 professores licenciados em Ciências Naturais são souberam citar nenhuma teoria da aprendizagem, alegando que não se lembravam delas com profundidade. Já nos estudos de Lucion, Frota e Silva (2012) nenhum dos entrevistados mencionou David Ausubel, afirmando que não estudaram este teórico em sua formação. Lucion, Frota e Silva (2012) afirmam que estes resultados podem levar a crer que a defasagem dos conteúdos trabalhados na disciplina de Psicologia da Educação, não possibilitou a internalização dos principais conceitos das teorias da aprendizagem. Assim, verificamos que as teorias da aprendizagem muitas vezes são de fato teorias que dificilmente são aplicadas na prática, seja por falta de conhecimento dos professores, ou por uma má formação inicial onde estas teorias não são discutidas satisfatoriamente. 
DOI: $\underline{\text { https://doi.org/10.46667/renbio.v13i1.267 }}$

\subsection{As disciplinas didático-pedagógicas versus conteúdo específico}

Nas entrevistas os professores também foram questionados sobre quais disciplinas lhes despertavam maior interesse durante a graduação. Todos afirmaram que eram as disciplinas de conteúdo específico, por se identificarem melhor ou por serem mais interessantes. Isso comprova com o que dizem Vasconcelos e Lima (2010) quando relatam que a maioria dos egressos dos cursos de licenciatura em Biologia não dá a real importância às disciplinas pedagógicas, e que isso pode ser ainda uma deficiência das universidades.

Segundo Gatti (2016) é preciso pensar no equilíbrio entre a área específica e os fundamentos pedagógicos, além dos requisitos da formação inicial. Na maioria dos cursos de licenciatura os componentes curriculares de cunho pedagógico possuem uma carga-horária expressivamente menor do que aqueles relacionados aos conhecimentos específicos, mas é necessário que haja a valorização e o interesse por parte dos graduandos das disciplinas didático-pedagógicas, uma vez que elas são fundamentais a sua formação.

Em algumas falas é possível notar uma aversão dos professores com relação às disciplinas didático-pedagógicas, quando questionados sobre as motivações de suas preferências das disciplinas de conteúdo específico em detrimento das disciplinas didáticaspedagógicas, como vemos na fala de P1 e P2:

Detestava as didáticas, eu não gostava dessa parte de pedagogia, eu não tinha afinidade nenhuma, metodologias de ensino achava chato, prática também achava um saco. Na verdade eu queria fazer bacharelado de biologia, mas tinha algumas dificuldades de locomoção e eu acabei indo para sala de aula mesmo (P1).

(...) logo eu não fiz magistério e a didática eu não gostava, eu achava bem melhor a parte específica, quem fez magistério talvez se identificasse melhor com as pedagógicas, eu odiava, principalmente na psicologia quando ia falar de vygotsky, aqueles teóricos todos eu odiava (P2).

Vasconcelos e Lima (2010) afirmam que a falta de identificação com o curso pode ainda acarretar na formação de profissionais insatisfeitos e de menor competência na docência no nível básico. Estes profissionais devem considerar que optando por um curso de licenciatura estarão se formando professores, e para o exercício dessa profissão é necessário o saber sobre todos os aspectos que envolvem a prática do ensino-aprendizagem. Contudo, é papel das universidades mostrar a importância destas disciplinas, sempre buscando despertar nos graduandos uma reflexão sobre a relevância e o comprometimento com o exercício da profissão docente.

Dos 10 entrevistados 08 afirmaram que as disciplinas didático-pedagógicas não eram ensinadas de forma atrativa, uma professora relatou que as disciplinas pedagógicas:

(...) não era aquela coisa atrativa porque não ensinava você a "ser professor", na minha opinião eu aprendi a ser professora em sala de aula (P4). 
DOI: https://doi.org/10.46667/renbio.v13i1.267

Com base nessa fala podemos destacar dois pontos, o primeiro versa sobre a responsabilidade pelo dinamismo das aulas e da atratividade das disciplinas pedagógicas que acaba recaindo injustamente ou não no docente universitário, o qual assume o papel de mediador entre a universidade e a educação básica, já que é ele quem apresenta e orienta o licenciando à profissão. O segundo ponto importante refere-se à formação do professor durante a prática docente. Depois de formados, a prática será responsável por demonstrar aos sujeitos as necessidades de aprimoramento constante para o exercício da docência (MACENHAN; TOZETTO; BRANDT, 2016). A formação do professor é complexa e contínua, porém muitos acabam tendo que "aprender" a ser professor apenas quando se veem na sala de aula tendo que enfrentar dificuldades e obstáculos que poderiam ser amenizados se eles dessem importância às disciplinas didático-pedagógicas na sua formação inicial.

\section{Considerações finais}

Foi verificado que os professores de Biologia da rede estadual de ensino do município de Surubim, Pernambuco, possuem um conhecimento fragmentado sobre as teorias da aprendizagem. Esta falta de conhecimento pode ter sido ocasionada pela falta de interesse pelas disciplinas pedagógicas, durante a sua formação inicial. Contudo, o professor está em constante formação podendo recorrer a cursos de aperfeiçoamento, especialização, entre outros. É importante enfatizar a importância e dedicação que os teóricos da educação tiveram ao estudar os processos de como o ser humano aprende, e que estes conhecimentos contribuem para uma prática pedagógica bem fundamentada. Assim, conhecer as teorias da aprendizagem poderia auxilia-los a compreender melhor como ocorre a aprendizagem humana e assim facilitar os processos de aprendizagem em sala de aula.

Além disso, é indispensável que na formação inicial dos professores seja enfatizado a importância das disciplinas didático pedagógicas para formação profissional dos discentes, apesar de muitos terem a preferência pelas disciplinas específicas da Biologia, como vimos no nosso estudo, é importante deixar claro que os discentes estão em cursos de licenciatura e até mesmo as instituições devem fornecer informações sobre a importância desta modalidade de formação, a fim de não criar lacunas nos conhecimentos pedagógicos dos futuros professores, podendo influenciar na qualidade de sua prática.

Contudo, não podemos julgar a prática pedagógica do professor de Biologia que não possui um conhecimento aprofundado das teorias da aprendizagem, pois, entendemos que a sua prática pedagógica é um reflexo de um conjunto de experiências dentro de um contexto individual que acaba corroborando com a sua prática. Porém, os futuros docentes como os egressos dos cursos de licenciatura devem não somente priorizar as disciplinas de conteúdo específicos de sua área, como também refletir que a sua profissão envolve seres humanos únicos, e que esse trabalho requer dele diversos saberes que podem ainda ser insuficientes para resolver toda a complexidade que perpassa uma sala de aula. 
DOI: $\underline{\text { https://doi.org/10.46667/renbio.v13i1.267 }}$

Deste modo, não defendemos a ideia de que para ser um bom professor deve-se conhecer e conceituar todas as teorias da aprendizagem, pois cada professor possui uma identidade própria, ele mesmo cria concepções sobre a importância da educação e de como se desenvolve os processos de ensino-aprendizagem. Contudo, os professores poderiam analisar, estudar e se aprofundar naquela teoria que ele melhor se identifica, e assim encontrar direcionamentos que possam fundamentar e auxiliar a sua prática de ensino. Retomando ao que diz Pittenger e Gooding (1977), os docentes devem examinar as semelhanças entre aquilo que acreditam referentes aos propósitos da educação e a informação disponível de como a aprendizagem se processa, a fim de sintetizar uma abordagem viável para o ensino. Sem a base de uma metodologia eficiente o profissional estará sujeito a se afundar em técnicas e métodos que podem ou não se adequar à sua personalidade, às necessidades e expectativas de seus alunos, ou às exigências da situação.

\section{Referências}

CARVALHO, D. DE C. As contribuições da psicologia para a formação de professores: algumas questões para debate. In: MARASCHIN, C; FREITAS, L; CARVALHO, D. C. DE. (Org.). Psicologia e Educação: multiversos sentidos, olhares e experiências. Porto Alegre: UFRGS, 2003.

COLL, C. Psicologia e currículo: uma aproximação psicopedagógica à elaboração do currículo escolar. 2. ed. São Paulo: Ática, 1997.

EMMEL, R; KRUL, A. J. As Teorias da aprendizagem frente aos professores da Educação Básica. Revista Di@logus, Cruz Alta. v. 1, n. 2, 2012.

GATTI, B. A. Formação de professores: condições e problemas atuais. Revista Internacional de Formação de Professores - RIPF, Itapetininga, v. 1, n. 1, p. 161-171, 2016.

IBGE. Censo Demográfico de 2018. Disponível em: http://ibge.gov.br/cidadesat/xtras/perfil.php?lang=\&codmun=261450\&search=pernambuco|su rubim. Acesso em: 26 jan. 2019.

LEFRANÇOIS, G. R. Teorias da aprendizagem. 5 ed. Tradução de Vera Magyar. São Paulo: Cengage Learning, 2012.

LUCION, C. DA S; FROTA, P. R; SILVA, R. DA. Teorias da aprendizagem: contribuições para a prática docente em Ciências Naturais. Revista Linhas, Florianópolis, v. 13, n. 2, jul./dez. 2012.

MACENHAN, C; TOZETTO, S. S; BRANDT, C. F. Formação de professores e prática pedagógica: uma análise sobre a natureza dos saberes docentes. Práxis Educativa, Ponta Grossa, v. 11, n. 2, p. 505-525, maio/ago. 2016

MINAYO, M. C de S. O desafio do conhecimento: pesquisa qualitativa em saúde. São Paulo-Rio de Janeiro, HUCITEC-ABRASCO, 1992. 
DOI: $\underline{\text { https://doi.org/10.46667/renbio.v13i1.267 }}$

MINAYO, M. C. S. (Org.) Pesquisa Social. Teoria, método e criatividade. 21 ed. Petrópolis: Vozes, 2002.

MOLON, S. A. A introdução de Vygotsky na psicologia. In: MOLON, S. A. Subjetividade e constituição do sujeito. São Paulo: Educ/Fapesp, 1999.

MOREIRA, M. A. Teorias de aprendizagem. 2. ed. ampl. São Paulo: E.P.U, 2015.

MOREIRA, M. A; MASINI, E. F. S. Aprendizagem significativa: a teoria de David Ausubel. São Paulo: Moraes, 1982.

NETTO, A. P; COSTA, O. S. A importância da psicologia da aprendizagem e suas teorias para o campo do ensino-aprendizagem. Fragmentos de Cultura, Goiânia, v. 27, n. 2, p. 216224, abr./jun. 2017.

NOGUEIRA, M. O. G; LEAL, D. Teorias da aprendizagem: um encontro entre os pensamentos filosófico, pedagógico e psicológico. 2 ed. Curitiba: InterSaberes, 2015.

NUNES, A. I; SILVEIRA, R. N. Psicologia da aprendizagem: processos, teorias e contextos. Brasília: Líber Livros, 2008.

OGASAWARA, J. S. V. O conceito de aprendizagem de Skinner e Vygotsky: um diálogo possível. 2009. Trabalho de Conclusão de Curso (Graduação em Pedagogia) - Universidade do Estado da Bahia, Salvador, 2009.

OLIVEIRA, M. M. Como fazer projetos, relatórios, monografias, dissertações e teses. 5. ed. Rio de Janeiro: Elsevier, 2011.

PITTENGER, O. E. GOODING, C. T. Teorias da aprendizagem na prática educacional: uma integração de teoria psicológica e filosofia educacional. São Paulo: EPU, 1977.

SCHEID, N. M. J. A contribuição da história da biologia na formação inicial de professores de ciências biológicas. 2006. Tese (Doutorado em Educação Científica e Tecnológica) - Universidade Federal de Santa Catarina, Florianópolis, SC, 2006.

SCHULTZ, D. P; SCHULTZ, S. E. História da psicologia moderna. 8. ed. São Paulo: Thomson Learning, 2006.

SKINNER, B. F. Ciência e comportamento humano. 11.ed. Tradução de João Carlos Todorov e Rodolfo Azzi. São Paulo: M. Fontes, 2003.

TARDIF, M. Saberes docentes e formação profissional. 9. ed. Petrópolis, RJ: Vozes, 2008.

VAILLANT, D; MARCELO, C. Ensinando a ensinar. As quatro etapas de uma aprendizagem. Curitiba: Editora UTFPR, 2012.

VASCONCELOS, S. D.; LIMA, K. E. C. O professor de biologia em formação: reflexão com base no perfil socioeconômico e perspectivas de licenciandos de uma universidade pública. Ciência \& Educação, Bauru, v. 16, n. 2, p. 323-340, 2010. 